\title{
BMJ Open Protocol for an investigator-blinded, randomised, 3-month, parallel-group study to compare the efficacy of intraoperative tendon sheath irrigation only with both intraoperative and postoperative irrigation in the treatment of purulent flexor tenosynovitis
}

\author{
Olli V Leppänen, Jarkko Jokihaara, Antti Kaivorinne, Jouni Havulinna, \\ Harry Göransson
}

To cite: Leppänen OV, Jokihaara J, Kaivorinne A, et al. Protocol for an investigator-blinded, randomised, 3-month, parallel-group study to compare the efficacy of intraoperative tendon sheath irrigation only with both intraoperative and postoperative irrigation in the treatment of purulent flexor tenosynovitis. BMJ Open 2015;5:e008824.

doi:10.1136/bmjopen-2015008824

- Prepublication history for this paper is available online. To view these files please visit the journal online (http://dx.doi.org/10.1136/ bmjopen-2015-008824).

Received 19 May 2015 Accepted 23 October 2015

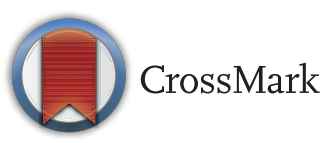

Department of Hand and Microsurgery, Tampere University Hospital, Tampere, Finland

Correspondence to Dr Olli V Leppänen; olli.v.leppanen@uta.fi

\section{ABSTRACT}

Introduction: The management of purulent flexor tenosynovitis of the hand consists of surgical debridement followed by antibiotic treatment. Usually, the debridement is carried out by irrigating the tendon sheath in a proximal to distal direction facilitated by two small incisions. It is unclear whether intraoperative irrigation by itself is adequate for healing or if it should be combined with postoperative irrigation in the ward. The hypothesis of this prospective randomised trial is that intraoperative catheter irrigation alone is as effective as a combination of intraoperative and postoperative intermittent catheter irrigation in the treatment of purulent flexor tenosynovitis.

Methods and analysis: In this investigator-blinded, prospective randomised trial, 48 patients suffering from purulent flexor tenosynovitis are randomised in two groups. Intraoperative catheter irrigation of the flexor tendon sheath and antibiotic treatment is identical in both groups, whereas only the patients in one group are subjected to intermittent postoperative catheter irrigation three times a day for 3 days. The primary outcome measure is total active range of movement of the affected finger after 3 months of surgery. The secondary outcome is the need for reoperation.

Ethics and dissemination: The research ethics committee of Pirkanmaa Hospital District has approved the study protocol. The protocol has been registered with ClinicalTrials.gov registry (\#NCT02320929). All participants will give written informed consent. The study results will elucidate the role of postoperative irrigation, which can be criticised as being labour consuming and unpleasant to the patient. The results of the study will be disseminated as a published article in a peer-reviewed journal.

Trial registration number: NCT02320929; pre-results.

\section{INTRODUCTION}

Background

Without immediate and adequate treatment, purulent flexor tenosynovitis of the hand may result in prolonged pain, stiffness and even permanent functional disability. Successful management of purulent flexor tenosynovitis is based on surgical debridement followed by intravenous antibiotic treatment. ${ }^{1}$ Several surgical methods have been described to remove the purulent debris from the flexor tendon sheath.

Originally, Kanavel ${ }^{2}$ reported extensive open debridement and irrigation, which today is applicable only in atypical or very advanced cases of purulent flexor tenosynovitis. ${ }^{1}$ Open irrigation is carried out using either a midaxial or Bruner approach to the tendon sheath, and, after debridement, the wound has been described as being loosely closed with sutures. ${ }^{1}$ Later, several authors ${ }^{3-11}$ described different surgical methods for catheter irrigation, which does not require extensive surgery and, at least theoretically, can facilitate faster recovery. The procedure involves irrigation of the tendon sheath in a proximal to distal direction facilitated by two small incisions; one proximal to the A1 pulley and one distal to the A4 pulley. ${ }^{12}$ Closure of the proximal wound using sutures, with catheter in place, has been suggested, while the distal wound is left open with a small Penrose drain. ${ }^{12}$ The closed-catheter irrigation is normally continued in the ward for $48 \mathrm{~h},{ }^{12}$ and it can be continuous, ${ }^{811}$ or intermittent. ${ }^{12}$ 
Delsignore et $a l^{8}$ reported a shorter hospital stay in patients who had been treated with intraoperative catheter irrigation when compared with open irrigation and debridement. However, no statistical analyses were conducted. Gutowski et al ${ }^{12}$ compared catheter irrigation with open irrigation and debridement, and found no statistically significant differences, although there was a statistically insignificant trend towards increased frequency of reoperations in the open irrigation and debridement group. All in all, no procedure has been shown to be superior to another, but, nevertheless, the consensus currently favours intraoperative catheter irrigation to open drainage. ${ }^{12}$

Most patients consider postoperative intermittent catheter irrigation in the ward an inconvenient and even painful procedure. ${ }^{13}$ The existence of the catheter may also delay the beginning of hand therapy. And, when considering the resources, although postoperative irrigation is a simple operation, it is still labour consuming. Lille $e$ t $a l^{13}$ conducted a retrospective study implying that intraoperative closed-catheter irrigation without postoperative irrigation might be as effective as a combination of intraoperative and postoperative irrigation. However, being retrospective, the study design suffers from several possible confounding effects (eg, sampling bias, observer bias).

\section{Primary aim}

The primary aim of this study is to find if intermittent postoperative catheter irrigation of the tendon sheath provides any additional benefit after intraoperative irrigation in the treatment of purulent flexor tenosynovitis.

\section{Hypothesis}

The hypothesis is that intraoperative closed-catheter irrigation alone is as effective as a combination of intraoperative and postoperative intermittent closed-catheter irrigation, in the treatment of purulent flexor tenosynovitis.

\section{METHODS AND ANALYSIS \\ Study design}

The trial is designed as a randomised, investigator and outcome assessor blinded single-centre trial with two parallel groups, and a primary end point of total range of movement of the affected finger after 3 months of surgery.

\section{Setting}

The recruitment of the patients will take place in the emergency department of the Tampere University Hospital, Tampere, Finland. The hospital is responsible for providing treatment of acute hand injuries and infections to 900000 inhabitants.

\section{Participants}

Inclusion criteria
- Clinical diagnosis of purulent flexor tenosynovitis with all four positive Kanavel signs ${ }^{2}$

- Symmetrical swelling of the entire digit

- Exquisite tenderness along the course of the tendon sheath

- Semiflexed posture of the digit

- Pain with attempted passive extension of the digit

- Age over 18 years

- Patient's willingness to participate in the study

Exclusion criteria

- High pressure, foreign body or chemical injuries that require open debridement

- Being a prisoner or military serviceman, or being mentally retarded or having other factors that may affect decision-making.

\section{Interventions}

After clinical examination, laboratory tests and filling in the baseline Quick Disabilities of the Arm, Shoulder and Hand Score (QuickDASH) form, ${ }^{14}$ tendon sheath irrigation is performed in the operating room identically in both study arms until randomisation. The procedure for intraoperative irrigation of the infected flexor tendon sheath is a modification of a guideline described by Gutowski $e t a l^{12}$ (figure 1). The flexor tendon sheath is opened proximal to the A1 pulley of the affected finger. Bacterial cultures are collected and the appearance of the exudate is noted. An 18-gauge angiocatheter is inserted percutaneously into the wound, approximately

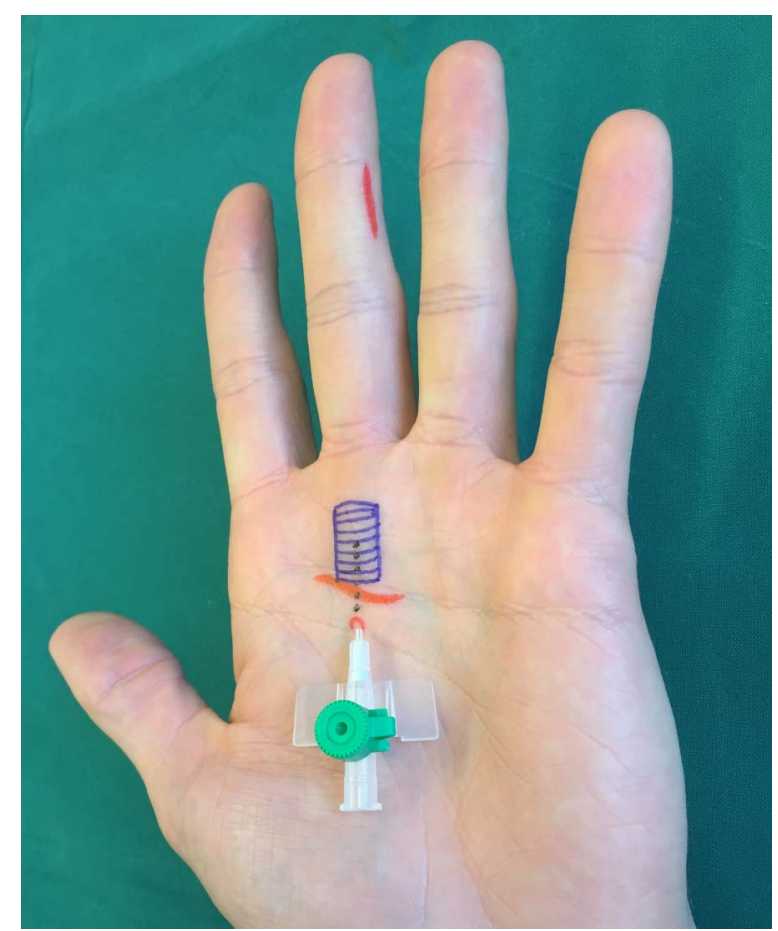

Figure 1 Schematic presentation of catheter irrigation. Incision (red) for placement of catheter tip (black) underneath A1 pulley (blue) and midaxial counter-incision (red) for outflow. 
$1 \mathrm{~cm}$ proximal to the incision. The tip of the catheter is placed within the sheath under the A1 pulley and the catheter is secured to the skin, using a suture. A counter incision is made midaxially at the level of the A4 pulley. A midaxial incision is favoured in order to avoid inconvenient scarring on the palmar surface of the finger. The tendon sheath is irrigated with $50 \mathrm{~mL}$ of physiological saline through a proximal catheter. The irrigation is continued until the output is clear. A small rubber drain is placed in both incisions to keep them open. If the thumb is involved, the catheter is placed in the flexor pollicis longus sheath distal to the carpal tunnel. If needed, a separate incision is made radial to the flexor carpi radialis tendon to drain the most proximal part of the tendon sheath. Depending on the group allocation after randomisation, the catheter is thereafter removed or retained. A normal hand dressing is applied.

For the patients of the intraoperative and postoperative irrigation group, the postoperative irrigation is performed by specially trained nurses in the ward, using $20 \mathrm{~mL}$ saline three times a day for 3 days. On day 3 , the tip of the removed angiocatheter is sent for bacterial culture. Hand therapy is initiated as early as possible in the ward. Antibiotic treatment is initiated in the operating room after the bacterial samples are collected. The primary antibiotic treatment is cefuroxime $1.5 \mathrm{~g}$ three times a day. The secondary choice (in case of allergy) is clindamycin. After discharge, the peroral antibiotic (primarily cephalexin) is continued for 10 days. The patients in both study arms receive identical written instructions for postoperative mobilisation.

\section{Outcome measures}

The patients have two follow-up visits at the outpatient clinic 4 weeks and 3 months postoperatively.

The primary outcome measurement is

- Total active range of movement of the most affected finger 3 months postoperatively

The secondary outcome variable is

- Need for reoperation during the first three postoperative months

Other outcome variables are

- QuickDASH score $^{14}$ (4 weeks and 3 months postoperatively)

- Pain at rest (visual analogue scale; 4 weeks and 3 months postoperatively).
Figure 2 The schedule of enrolment, interventions and assessments demonstrated in the SPIRIT figure.

\begin{tabular}{|c|c|c|c|c|c|c|}
\hline & \multicolumn{6}{|c|}{ STUDY PERIOD } \\
\hline & \multirow{2}{*}{$\begin{array}{c}\text { Enrolment } \\
0\end{array}$} & \multirow{2}{*}{$\begin{array}{c}\text { Pre-allocation } \\
0\end{array}$} & \multirow{2}{*}{$\begin{array}{c}\text { Allocation } \\
0\end{array}$} & \multicolumn{2}{|c|}{ Post-allocation } & \multirow{2}{*}{$\begin{array}{l}\text { Close-out } \\
\text { 3months }\end{array}$} \\
\hline TIMEPOINT & & & & 3days* & $4 w k s$ & \\
\hline \multicolumn{7}{|l|}{ ENROLMENT: } \\
\hline \multirow{2}{*}{$\begin{array}{l}\text { Eligibility screen } \\
\text { Informed consent }\end{array}$} & $x$ & & & & & \\
\hline & $x$ & & & & & \\
\hline Allocation & & & $x$ & & & \\
\hline \multicolumn{7}{|l|}{ INTERVENTIONS: } \\
\hline \multirow{2}{*}{$\begin{array}{r}\text { Intraoperative } \\
\text { catheter irrigation } \\
\\
\text { Postoperative } \\
\text { catheter irrigation }\end{array}$} & & $x$ & & & & \\
\hline & & & & $\mathrm{x}$ & & \\
\hline \multicolumn{7}{|l|}{ ASSESSMENTS: } \\
\hline $\begin{array}{l}\text { AROM of the most } \\
\text { affected finger }\end{array}$ & $x$ & & & $\mathrm{x}$ & $x$ & $\mathrm{x}$ \\
\hline $\begin{array}{l}\text { AROM of the } \\
\text { contralateral finger }\end{array}$ & $x$ & & & $x$ & $x$ & $x$ \\
\hline Pain at rest (VAS) & $\mathrm{x}$ & & & $\mathrm{x}$ & $\mathrm{x}$ & $x$ \\
\hline \multirow{2}{*}{$\begin{array}{l}\text { QuickDASH -score } \\
\text { Infection markers } \\
\text { (S-CRP,S- Leuc) }\end{array}$} & $x$ & & & $\mathrm{x}$ & $x$ & $x$ \\
\hline & $x$ & & & $x$ & & \\
\hline
\end{tabular}

*At discharge. The length of the hospital stay may differ depending on the clinical state. AROM; total range of movement

QuickDASH; Quick Disabilities of the Arm, Shoulder and Hand Score 


\section{Allocation and blinding}

The patients are stratified in four groups depending on the purulence of the exudate (clear vs murky or purulent) and age over 43 years or the presence of diabetes mellitus, peripheral vascular disease, or renal failure (yes vs no), which have been shown to be associated with poor outcome after purulent tenosynovitis. ${ }^{15}$ A block randomisation to two study arms (intraoperative irrigation only or intraoperative and postoperative irrigation) is carried out within these four groups in order to ensure even allocation. Only the statistician who carried out the randomisation is aware of the size of the block. The assignments are enclosed in opaque, sealed envelopes that are sequentially numbered for each stratification group.

The patient cannot be blinded. The operating surgeon is blinded until the randomisation. The randomisation is delayed to take place just after the intraoperative irrigation in order to ensure the longest possible blinding of the surgeon. The staff in the ward

Table 1 Items from the clinical trials.gov data set

\begin{tabular}{|c|c|}
\hline Data category & Information \\
\hline \multirow{2}{*}{$\begin{array}{l}\text { Primary registry and trial } \\
\text { identifying number }\end{array}$} & ClinicalTrials.gov \\
\hline & NCT02320929 \\
\hline $\begin{array}{l}\text { Date of registration in primary } \\
\text { registry }\end{array}$ & 8 December 2014 \\
\hline Date and version identifier & 29 August 2015, v.1.0 \\
\hline $\begin{array}{l}\text { Source(s) of monetary or } \\
\text { material support }\end{array}$ & - \\
\hline \multirow[t]{4}{*}{ Primary sponsor } & Tampere University Hospital \\
\hline & Teiskontie 35 \\
\hline & 33520 Tampere \\
\hline & Finland \\
\hline Secondary sponsor & University of Tampere \\
\hline Contact for public queries & Olli V Leppänen, email: olli.v.leppanen@uta.fi, Tel.: +358-3-31167745 \\
\hline Contact for scientific queries & Olli V Leppänen, email: olli.v.leppanen@uta.fi, Tel.: +358-3-31167745 \\
\hline Public title & $\begin{array}{l}\text { The treatment of purulent flexor tenosynovitis-is postoperative catheter irrigation } \\
\text { necessary? }\end{array}$ \\
\hline Scientific title & $\begin{array}{l}\text { An investigator-blinded, randomised, } 3 \text { months, parallel-group study to compare the } \\
\text { efficacy of intraoperative tendon sheath irrigation only with both intraoperative and } \\
\text { postoperative irrigation in the treatment of purulent flexor tenosynovitis }\end{array}$ \\
\hline Countries of recruitment & Finland \\
\hline $\begin{array}{l}\text { Health condition(s) or problem(s) } \\
\text { studied }\end{array}$ & Purulent flexor tenosynovitis \\
\hline Intervention(s) & $\begin{array}{l}\text { Intraoperative tendon sheath irrigation; intraoperative and postoperative tendon sheath } \\
\text { irrigation }\end{array}$ \\
\hline \multirow{6}{*}{$\begin{array}{l}\text { Key inclusion and exclusion } \\
\text { criteria }\end{array}$} & Ages eligible for study: $\geq 18$ years \\
\hline & Sexes eligible for study: both \\
\hline & Accepts healthy volunteers: no \\
\hline & Inclusion criteria: clinical diagnosis of purulent flexor tenosynovitis with all four positive \\
\hline & Kanavel signs \\
\hline & $\begin{array}{l}\text { Exclusion criteria: high-pressure, foreign body or chemical injuries that require open } \\
\text { debridement; being a prisoner or military serviceman, being mentally retarded or having } \\
\text { other factors that may affect decision-making }\end{array}$ \\
\hline \multirow[t]{5}{*}{ Study type } & Interventional \\
\hline & Allocation: randomised \\
\hline & Intervention model: parallel assignment \\
\hline & Masking: single blind (investigator, outcomes assessor) \\
\hline & Primary purpose: treatment \\
\hline Date of first enrolment & March 2015 \\
\hline Target sample size & 48 \\
\hline Recruitment status & Recruiting \\
\hline Primary outcome(s) & $\begin{array}{l}\text { Total range of movement of the affected finger (time frame: } 3 \text { months; not designated as } \\
\text { safety issue) }\end{array}$ \\
\hline Key secondary outcomes & $\begin{array}{l}\text { Need for reoperation (time frame: } 3 \text { months; not designated as safety issue); QuickDASH } \\
\text { (time frame: } 3 \text { months; not designated as safety issue); pain at rest (time frame: } 3 \text { months; } \\
\text { not designated as safety issue) }\end{array}$ \\
\hline
\end{tabular}


cannot be blinded. The investigator in the outpatient clinic is blinded, because he/she has not participated in the treatment (neither in the operation nor in the ward).

\section{Data collection and monitoring}

The patient recruitment and treatment is performed by senior hand surgeons or hand surgery residents of the Tampere University Hospital, Tampere, Finland. The collection of narrative and objective data is saved in a password-protected database. Only members of the Data Monitoring Board have access to the database during the study period. All adverse events (AE) will be documented in detail, and will be reported to the Data Monitoring Board. The principal investigator will report the $\mathrm{AE}$ within $24 \mathrm{~h}$ after it becomes known. The investigators are responsible for making the final decision to terminate the trial. Participants who suffer an AE will be given adequate medical treatment and will be entitled to seek compensation from the Finnish Patient Insurance Centre.

\section{Sample size}

A total of 48 patients (24 patients/group) are needed for the study. This is based on the power calculation: $\mathrm{p}=0.05, \mathrm{p}=0.8$, group difference $20 \%$ (in the total range of movement at 3 months postoperatively) and relative SD $20 \%$, drop out $25 \%$.

\section{Patient timeline}

Figure 2 shows the patient timeline.

\section{Statistical analysis}

All analyses will be performed according to the intention to treat principle. Analysis of variance is used for all numeric variables (range on movement, QuickDASH-score, pain score). The $\chi^{2}$ test is used in the comparison of incidences of reoperation. For all tests, we will use two-sided $\mathrm{p}$ values with a $\mathrm{p}<0.05$ level of significance.

\section{DISCUSSION}

Postoperative intermittent irrigation of the infected tendon sheath is a standard procedure to treat purulent flexor tenosynovitis. ${ }^{1}$ There is insufficient evidence that this labour-consuming and unpleasant procedure is beneficial to the patient's recovery. It also delays the beginning of hand therapy, since the catheter on the volar aspect of the hand blocks active and passive flexion exercises. In this era of multiresistant bacterial strains, any unnecessary handling of fluids, wounds and foreign bodies (eg, plastic angiocatheter) in hospital wards is a potential threat of superinfection. The objective of this prospective randomised study is to elucidate the necessity of postoperative irrigation.

Currently, prospective randomised trials are considered the best methodological approach for evaluating the efficacy of a specific intervention. The limitations of this study are: the patients cannot be blinded to the intervention and the statistical power is not adequate to show clinically relevant differences in reoperation rate, since the incidence is most likely low in both study arms. Since the requirement to include the patient in this study is that all four Kanavel signs ${ }^{2}$ are positive, there is a chance that some patients having purulent tenosynovitis but lacking some of the signs may be excluded. The selection of our tertiary outcome variable, QuickDASH, ${ }^{14}$ can also be questioned, since the Michigan Hand Outcomes Questionnaire (MHQ) has been postulated to be slightly more sensitive to functional changes concerning hand injuries. ${ }^{16}$ However, we justify our selection by the fact that the MHQ has not been validated in Finnish, and DASH has been shown to be similarly reproducible and valid for finger and wrist disorders as the MHQ. ${ }^{17}$

\section{ETHICS AND DISSEMINATION}

The protocol has been registered to ClinicalTrials.gov registry (\#NCT02320929) (table 1). Any protocol modifications will be documented in the ClinicalTrials.gov registry. None of the authors have any conflict of interest to declare. The patient will be asked for consent before entering the study and can discontinue the study at any time without any obligation to report a reason for the decision. Intraoperative catheter irrigation can be considered the gold standard when treating purulent flexor tenosynovitis. Postoperative irrigation is a normal procedure, supposedly benefiting recovery, but it is not imperative, and there is some evidence that it might be redundant. ${ }^{13}$ The study results will elucidate the role of postoperative irrigation. If postoperative irrigation is found to be redundant, it may simplify the treatment in those units where it has been a standard protocol. The results of the study will be disseminated as a published article in a peer-reviewed journal. The study will be implemented and reported in line with the CONSORT statement.

Contributors OVL conceived of the study. All the authors participated in designing the study. Heidi Huhtala provided statistical expertise in the clinical trial design and carried out the randomisation. All the authors contributed to refinement of the study protocol and approved the final version.

Funding This work is supported by a grant from the Competitive State Research Financing of the Expert Responsibility area of Tampere University Hospital (grant number 9T011).

Competing interests None declared.

Ethics approval The research ethics committee of Pirkanmaa Hospital District has approved the study protocol.

Provenance and peer review Not commissioned; externally peer reviewed.

Open Access This is an Open Access article distributed in accordance with the Creative Commons Attribution Non Commercial (CC BY-NC 4.0) license, which permits others to distribute, remix, adapt, build upon this work noncommercially, and license their derivative works on different terms, provided the original work is properly cited and the use is non-commercial. See: http:// creativecommons.org/licenses/by-nc/4.0/ 


\section{REFERENCES}

1. Draeger RW, Bynum DK Jr. Flexor tendon sheath infections of the hand. J Am Acad Orthop Surg 2012;20:373-82.

2. Kanavel AB. Infections of the hand: the symptoms, signs, and diagnosis of tenosynovitis and major fascial-space abscesses. 6th edn. Philadelphia, PA: Lea and Febiger, 1933.

3. Dickson-Wright A. Tendon sheath infection. Proc R Soc Med 19431944;37:504-5.

4. Besser MI. Digital flexor tendon irrigation. Hand 1976;8:72.

5. Carter SJ, Burman SO, Mersheimer WL. Treatment of digital tenosynovitis by irrigation with peroxide and oxytetracycline: review of nine cases. Ann Surg 1966;163:645-50.

6. Pollen AG. Acute infection of the tendon sheaths. Hand 1974;6:21-5.

7. Neviaser RJ. Closed tendon sheath irrigation for pyogenic flexor tenosynovitis. J Hand Surg Am 1978;3:462-6.

8. Delsignore JL, Ritland D, Becker DR, et al. Continuous catheter irrigation for the treatment of suppurative flexor tenosynovitis. Conn Med 1986;50:503-6.

9. Gosain AK, Markison RE. Catheter irrigation for treatment of pyogenic closed space infections of the hand. Br J Plast Surg 1991;44:270-3.

10. Nemoto K, Yanagida M, Nemoto T. Closed continuous irrigation as a treatment for infection in the hand. J Hand Surg Br 1993;18:783-9.
11. Harris PA, Nanchahal J. Closed continuous irrigation in the treatment of hand infections. J Hand Surg Br 1999;24: 328-33.

12. Gutowski KA, Ochoa O, Adams WP Jr. Closed-catheter irrigation is as effective as open drainage for treatment of pyogenic flexor tenosynovitis. Ann Plast Surg 2002;49:350-4.

13. Lille S, Hayakawa T, Neumeister MW, et al. Continuous postoperative catheter irrigation is not necessary for the treatment of suppurative flexor tenosynovitis. J Hand Surg Br 2000;25:304-7.

14. Disabilities of the Arm, Shoulder and Hand Outcome Measure. http://dash.iwh.on.ca/

15. Pang HN, Teoh LC, Yam AK, et al. Factors affecting the prognosis of pyogenic flexor tenosynovitis. J Bone Joint Surg Am 2007;89:1742-8.

16. Horng YS, Lin MC, Feng CT, et al. Responsiveness of the Michigan Hand Outcomes Questionnaire and the Disabilities of the Arm, Shoulder, and Hand questionnaire in patients with hand injury. $J$ Hand Surg Am 2010;35:430-6.

17. Dias JJ, Rajan RA, Thompson JR. Which questionnaire is best? The reliability, validity and ease of use of the Patient Evaluation Measure, the Disabilities of the Arm, Shoulder and Hand and the Michigan Hand Outcome Measure. J Hand Surg Eur Vol 2008;33:9-17 